\title{
Predictive Factors for Smartphone Dependence: Relationship to Demographic Characteristics, Chronotype, and Depressive State of University Students
}

\author{
Masahiro Toda ${ }^{*}$, Nobuhiro Nishio², Tatsuya Takeshita ${ }^{2}$ \\ ${ }^{1}$ Graduate School of Human Life Sciences, Notre Dame Seishin University, Okayama, Japan \\ ${ }^{2}$ Department of Public Health, Wakayama Medical University, Wakayama, Japan \\ Email: *mt@post.ndsu.ac.jp
}

Received 21 October 2015; accepted 14 December 2015; published 17 December 2015

Copyright (C) 2015 by authors and Scientific Research Publishing Inc.

This work is licensed under the Creative Commons Attribution International License (CC BY). http://creativecommons.org/licenses/by/4.0/

(c) (i) Open Access

\begin{abstract}
We investigated factors contributing to smartphone dependence. To 196 medical university students, we administered a set of self-reporting questionnaires designed to evaluate demographic characteristics, smartphone dependence, chronotype, and depressive state. Smartphone dependence was evaluated using the Wakayama Smartphone-Dependence Scale (WSDS) with 3 subscales: Subscale 1, immersion in Internet communication; Subscale 2, using a smartphone for extended periods of time and neglecting social obligations and other tasks; Subscale 3, using a smartphone while doing something else and neglect of etiquette. Multiple regression analyses revealed that living in a family, eveningness, and presence of depression were associated with Subscale 1, that living in a family and eveningness were also associated with Subscale 2, and that being a man was associated with Subscale 3 . These findings suggest that smartphone dependence can be predicted by factors such as gender, mode of residence, chronotype, or depressive state.
\end{abstract}

\section{Keywords}

Chronotype, Depressive State, Smartphone, University Students, Wakayama Smartphone-Dependence Scale (WSDS)

\section{Introduction}

Along with the rapid proliferation of mobile phones, various social issues have arisen, including excessive use "Corresponding author.

How to cite this paper: Toda, M., Nishio, N. and Takeshita, T. (2015) Predictive Factors for Smartphone Dependence: Relationship to Demographic Characteristics, Chronotype, and Depressive State of University Students. Open Journal of Preventive Medicine, 5, 456-462. http://dx.doi.org/10.4236/ojpm.2015.512051 
or even dependence. Viewing compulsive mobile phone use as a type of technostress, to gauge mobile phone dependence (we define it in terms of two factors: excessive use and use of mobile phones in public places even when such use is considered to be a nuisance), we designed a questionnaire, the MPDQ (Mobile Phone Dependence Questionnaire) [1]. So far, we have used it to elucidate associations between mobile phone dependence and individual characteristics such as health-related lifestyle, chronotype, patterns of behavior, or depressive state [2]-[4].

Meanwhile, smartphones, which first became widely available in Japan in 2008, have rapidly come into widespread use. At the end of 2013, the household penetration in Japan was 62.6\% [5]. Smartphones are more like tablet computers than mobile phones, and therefore may herald another change in the way mobile telecommunications are used. To try and characterize these changes, we recently developed a new scale for gauging smartphone dependence, the Wakayama Smartphone-Dependence Scale (WSDS), and confirmed its reliability and validity [6]. The scale consists of three dimensions, and we think it is a useful tool for rating smartphone dependence.

Although a previous study has reported that smartphone overuse was associated with depression, anxiety, and poor sleep quality [7], there are still very few studies investigating associations between smartphone use and individual characteristics. In the present study, at the outset, we examined associations between smartphone dependence and demographic characteristics, chronotype, and depressive state. Chronotype refers to preference for sleep-wake timing: for example, morning types go to bed, get up, and experience peak alertness and performance earlier in the day than do evening types [8]. Since excessive use of smartphones in bed before sleep may cause delayed sleep phase [9] [10], to elucidate predictive factors for smartphone dependence, evaluation of chronotype is important. Furthermore, it has been suggested that depressive state may be associated with both mobile phone dependence and eveningness [3] [11].

\section{Materials and Methods}

\subsection{Subjects}

For the study, approved by the Ethics Committee of Wakayama Medical University, we recruited 196 medical university students from our class. After informed consent was obtained, the participants filled out a set of selfreporting questionnaires designed to evaluate smartphone dependence, chronotype, and depressive state. Of 185 respondents who possessed smartphones, 175 respondents properly completed all the questionnaire items. Statistical analysis was performed for 126 respondents (77 males, 49 females) who used smartphones mainly to access the Internet. Mean $( \pm S D)$ age for males was $21.2 \pm 1.8$ years and for females $20.5 \pm 1.4$ years.

\subsection{Smartphone Dependence}

Smartphone dependence was evaluated using the WSDS [6], a 21-item self-rating scale with 3 subscales (each comprising 7 items): Subscale 1, immersion in Internet communication; Subscale 2, using a smartphone for extended periods of time and neglecting social obligations and other tasks; Subscale 3, using a smartphone while doing something else and neglect of etiquette. Each response is scored on a Likert scale $(0,1,2,3)$. Likert scores for each item were then summed to provide subscales (ranging from 0 to 21) and overall (ranging from 0 to 63) scores of smartphone dependence. Higher scores indicate greater dependence.

\subsection{Chronotype}

Chronotype was assessed using the Horne and Östberg Morningness-Eveningness Questionnaire (MEQ) [12], a self-rating questionnaire which consists of 19 items with total score ranging from 16 to 86 . Higher scores indicate greater morningness.

\subsection{Depressive State}

Depressive state was assessed using the Beck Depression Inventory-II (BDI-II) [13], a self-rating questionnaire which consists of 21 items with total score ranging from 0 to 63. Subjects were categorized as having either absence or presence of depression; persons with scores of 14 points or more are placed in the presence category [13]. 


\subsection{Statistical Analysis}

Before statistical analysis, normal distribution was tested by Kolmogorov-Smirnov testing. Valid distributions were obtained for the WSDS total and subscale scores. Standard multiple regression analyses were conducted with the WSDS and each subscale serving as the criterion variable. Predictor variables were demographic characteristics (age, gender and mode of residence), chronotype, and depressive state. Statistical significance was set at $p<0.05$.

\section{Results}

Table 1 shows scores for each questionnaire. Males had statistically significantly higher Subscale 3 scores than females $(t=2.79, p<0.01)$. Meanwhile, MEQ scores were statistically significantly lower in males than in females $(t=-2.44, p<0.05)$. There was no significant difference between males and females in mode of residence and depressive state (Table 2).

Table 3 shows multiple regression analyses to identify variables which predict total and subscale scores for the WSDS. All multiple regressions were statistically significant, and the coefficients of determination were from 0.11 to 0.18 . Living in a family and low MEQ scores were associated with Subscale $1(\beta=-0.247, p<$ 0.01 and $\beta=-0.231, p<0.01$, respectively), Subscale $2(\beta=-0.225, p<0.01$ and $\beta=-0.324, p<0.001$, respectively), and total WSDS scores $(\beta=-0.223, p<0.01$ and $\beta=-0.308, p<0.001$, respectively). In addition, presence of depression was also associated with Subscale 1 scores $(\beta=0.259, p<0.01)$. Being male, on its own, predicted Subscale 3 scores $(\beta=-0.239, p<0.01)$.

\section{Discussion}

Subscales 1 and 2 were associated with eveningness. Previous studies have reported that excessive use of mobile phones at night may delay the sleep phase [9] [10]. This may be associated with display brightness [14]. It has been reported that exposure light at night increases human alertness and suppresses melatonin secretion [15]. It is, however, also possible that people who use digital media at night already have a delayed sleep pattern and

Table 1. Questionnaire scores for smartphone dependence and chronotype.

\begin{tabular}{|c|c|c|c|c|}
\hline & & Males $(\mathrm{n}=77)$ & Females $(n=49)$ & $p^{*}$ \\
\hline \multicolumn{5}{|c|}{ Wakayama Smartphone-Dependence Scale (WSDS) } \\
\hline \multicolumn{2}{|l|}{ Subscale 1} & $5.6 \pm 3.8$ & $5.8 \pm 4.0$ & 0.82 \\
\hline \multicolumn{2}{|l|}{ Subscale 2} & $10.0 \pm 4.0$ & $8.8 \pm 3.8$ & 0.09 \\
\hline \multicolumn{2}{|l|}{ Subscale 3} & $14.8 \pm 3.6$ & $13.0 \pm 3.4$ & $<0.01$ \\
\hline \multicolumn{2}{|l|}{ Total } & $30.5 \pm 8.5$ & $27.6 \pm 9.4$ & 0.08 \\
\hline \multicolumn{2}{|c|}{ Horne and Östberg Morningness-Eveningness Questionnaire (MEQ) } & $45.8 \pm 6.5$ & $49.7 \pm 9.9$ & $<0.05$ \\
\hline \multicolumn{5}{|c|}{$\begin{array}{l}\text { Values are expressed as mean } \pm \text { SD. "Student's } t \text { test. Subscale 1, Immersion in Internet communication; Subscale 2, Using a smartphone for extende } \\
\text { periods of time and neglecting social obligations and other tasks; Subscale 3, Using a smartphone while doing something else and neglect of etiquette }\end{array}$} \\
\hline & Males, n (\%) & Females, n (\%) & $\chi^{2}$ & $p$ \\
\hline \multicolumn{5}{|c|}{ Mode of residence } \\
\hline In a family & $20(26.0)$ & $20(40.8)$ & \multirow{2}{*}{3.04} & \multirow{2}{*}{0.12} \\
\hline Solitary & $57(74.0)$ & $29(59.2)$ & & \\
\hline \multicolumn{5}{|l|}{ Depression } \\
\hline Absent & 66 (85.7) & $42(85.7)$ & \multirow{2}{*}{0} & \multirow{2}{*}{1.00} \\
\hline Present & $11(14.3)$ & 7 (14.3) & & \\
\hline
\end{tabular}


Table 3. Multiple regression models predicting smartphone dependence.

\begin{tabular}{|c|c|c|c|c|c|c|c|c|}
\hline & \multicolumn{2}{|c|}{ Subscale 1} & \multicolumn{2}{|c|}{ Subscale 2} & \multicolumn{2}{|c|}{ Subscale 3} & \multicolumn{2}{|c|}{ Total WSDS } \\
\hline & $\beta$ & $p$ & $\beta$ & $p$ & $\beta$ & $p$ & $\beta$ & $p$ \\
\hline Age & -0.055 & 0.51 & -0.123 & 0.15 & -0.139 & 0.12 & -0.135 & 0.11 \\
\hline Gender (1, female; 0, male) & 0.025 & 0.77 & -0.134 & 0.13 & -0.239 & $<0.01$ & -0.146 & 0.10 \\
\hline $\begin{array}{l}\text { Mode of residence } \\
\text { (1, solitary; } 0 \text {, in a family) }\end{array}$ & -0.247 & $<0.01$ & -0.225 & $<0.01$ & -0.042 & 0.64 & -0.223 & $<0.01$ \\
\hline MEQ scores & -0.231 & $<0.01$ & -0.324 & $<0.001$ & -0.158 & 0.08 & -0.308 & $<0.001$ \\
\hline $\begin{array}{l}\text { Depression } \\
\text { (1, present; 0, absent) }\end{array}$ & 0.259 & $<0.01$ & 0.008 & 0.92 & -0.106 & 0.22 & 0.072 & 0.39 \\
\hline Coefficient of determination & & $R^{2}=0.18$ & & $R^{2}=0.17$ & & $R^{2}=0.11$ & & $R^{2}=0.17$ \\
\hline & $F=5.15$ & $p<0.001$ & $F=4.97$ & $p<0.001$ & $F=2.95$ & $p<0.05$ & $F=5.08$ & $p<0.001$ \\
\hline
\end{tabular}

WSDS, Wakayama Smartphone-Dependence Scale; Subscale 1, Immersion in Internet communication; Subscale 2, Using a smartphone for extended periods of time and neglecting social obligations and other tasks; Subscale 3, Using a smartphone while doing something else and neglect of etiquette.

cannot get to sleep at a designated bedtime [16]. In addition, it has been suggested that increased frequency of eveningness may reflect premorbid traits of or vulnerability to depression [11]. As a form of depression avoidance, therefore, evening types may be immersing themselves in Internet communication. Our recent study that found an association between mobile phone dependency and depression might support this hypothesis [3]. Because of the cross-sectional design, however, this study is unable to clarify causal direction. This point requires consideration in future studies.

Contrary to our expectations, Subscales 1 and 2 were associated with living in a family. It has been suggested that, for high-school students, parental monitoring is a major inhibitor of Internet addiction [17]. In addition, we have found that the loneliness of living alone might be associated with mobile phone dependence [18]. It is possible, therefore, that our present findings, are peculiar to our sample population. For example, our respondents who lived alone may have had to spend lots of time on housework or part-time work. A previous study has found that leisure boredom may contribute to Internet addiction [17]. On the other hand, children who continue to live at home as university students may be subject to less parental interference. Thus, to clarify the cause of our discrepant findings, further studies including daily life and parent-child relationships are required.

Subscale 3 was associated with being male. In our previous study, males also scored more highly than females for: "When I am riding on a train or in similar situations, I tend to handle my mobile phone"; "Even while riding on trains, I make and receive calls"; and "I make mobile phone calls even late at night" [2]. On the other hand, a previous study found that, females, more than males, were tolerant toward mobile phone use in public places, and actually often used mobile phones in public spaces [19]. That study suggested and others [20] [21] that it may be due to gender difference in the nature of mobile phone use, females valuing mobile phones as a means of expression and social communication, while males make fewer calls for more purposeful conversations. Even so, all these studies, including ours, were not on smartphones. As mentioned previously, smartphones are entirely different from conventional mobile phones. To confirm our present findings, we need to wait for future studies.

This research has several limitations. First, all the subjects were medical students. The sample size was also too small to be representative of a cohort in the general population. The present findings cannot be assumed to apply to all young people. Second, coefficients of determination for the multiple regression models were not so high. Other factors should be investigated in future studies. Even so, particularly for adolescents, the potentially harmful effects of new media are still important concerns [22]. As data on smartphone dependence accumulate, it may become possible to provide more conclusive results.

\section{Conclusion}

In conclusion, the major finding of this study is that smartphone dependence can be predicted by factors such as gender, mode of residence, chronotype, or depressive state. The findings may be useful for providing smartphone guidance directed at young people. 


\section{References}

[1] Toda, M., Monden, K., Kubo, K. and Morimoto, K. (2004) Cellular Phone Dependence Tendency of Female University Students. Japanese Journal of Hygiene, 59, 383-386. http://dx.doi.org/10.1265/jjh.59.383

[2] Toda, M., Monden, K., Kubo, K. and Morimoto, K. (2006) Mobile Phone Dependence and Health-Related Lifestyle of University Students. Social Behavior and Personality, 34, 1277-1284. http://dx.doi.org/10.2224/sbp.2006.34.10.1277

[3] Toda, M. and Ezoe, S. (2013) Multifactorial Study of Mobile Phone Dependence in Medical Students: Relationship to Health-Related Lifestyle, Type A Behavior, and Depressive State. Open Journal of Preventive Medicine, 3, 99-103. http://dx.doi.org/10.4236/ojpm.2013.31012

[4] Toda, M., Nishio, N., Ezoe, S. and Takeshita, T. (2015) Chronotype and Smartphone Use among Japanese Medical Students. International Journal of Cyber Behavior, Psychology and Learning, 5, 77-83. http://dx.doi.org/10.4018/IJCBPL.2015040106

[5] Ministry of Internal Affairs and Communications (2014) White Paper: Information and Communications in Japan, 2014.

[6] Toda, M., Nishio, N. and Takeshita, T. (2015) Development of a New Scale for Gauging Smartphone Dependence. Japanese Journal of Hygiene, 70, 259-263. http://dx.doi.org/10.1265/jjh.70.259

[7] Demirci, K., Akgönül, M. and Akpınar, A. (2015) Relationship of Smartphone Use Severity with Sleep Quality, Depression, and Anxiety in University Students. Journal of Behavioral Addictions, 4, 85-92. http://dx.doi.org/10.1556/2006.4.2015.010

[8] Kerkhof, G.A. (1985) Inter-Individual Differences in the Human Circadian System: A Review. Biological Psychology, 20, 83-112. http://dx.doi.org/10.1016/0301-0511(85)90019-5

[9] Brunborg, G.S., Mentzoni, R.A., Molde, H., Myrseth, H., Skouverøe, K.J., Bjorvatn, B. and Pallesen, S. (2011) The Relationship between Media Use in the Bedroom, Sleep Habits and Symptoms of Insomnia. Journal of Sleep Research, 20, 569-575. http://dx.doi.org/10.1111/j.1365-2869.2011.00913.x

[10] Fossum, I.N., Nordnes, L.T., Storemark, S.S., Bjorvatn, B. and Pallesen, S. (2014) The Association between Use of Electronic Media in Bed before Going to Sleep and Insomnia Symptoms, Daytime Sleepiness, Morningness, and Chronotype. Behavioral Sleep Medicine, 12, 343-357. http://dx.doi.org/10.1080/15402002.2013.819468

[11] Drennan, M.D., Klauber, M.R., Kripke, D.F. and Goyette, L.M. (1991) The Effects of Depression and Age on the Horne-Ostberg Morningness-Eveningness Score. Journal of Affective Disorders, 23, 93-98. http://dx.doi.org/10.1016/0165-0327(91)90096-B

[12] Horne, J.A. and Östberg, O. (1976) A Self-Assessment Questionnaire to Determine Morningness-Eveningness in Human Circadian Rhythms. International Journal of Chronobiology, 4, 97-110.

[13] Beck, A.T., Steer, R.A. and Brown, G.K. (1996) Manual for the Beck Depression Inventory-II. Psychological Corporation, San Antonio.

[14] Suganuma, N., Kikuchi, T., Yanagi, K., Yamamura, S., Morishima, H., Adachi, H., Kumano-go, T., Mikami, A., Sugita, Y. and Takeda, M. (2007) Using Electronic Media before Sleep Can Curtail Sleep Time and Result in Self-Perceived Insufficient Sleep. Sleep and Biological Rhythms, 5, 204-214. http://dx.doi.org/10.1111/j.1479-8425.2007.00276.x

[15] Zeitzer, J.M., Dijk, D.J., Kronauer, R., Brown, E. and Czeisler, C. (2000) Sensitivity of the Human Circadian Pacemaker to Nocturnal Light: Melatonin Phase Resetting and Suppression. The Journal of Physiology, 526, 695-702. http://dx.doi.org/10.1111/j.1469-7793.2000.00695.x

[16] Cain, N. and Gradisar, M. (2010) Electronic Media Use and Sleep in School-Aged Children and Adolescents: A Review. Sleep Medicine, 11, 735-742. http://dx.doi.org/10.1016/j.sleep.2010.02.006

[17] Lin, C.H., Lin, S.L. and Wu, C.P. (2009) The Effects of Parental Monitoring and Leisure Boredom on Adolescents' Internet Addiction. Adolescence, 44, 993-1004.

[18] Toda, M., Ezoe, S., Nishi, A., Mukai, T., Goto, M. and Morimoto, K. (2008) Mobile Phone Dependence of Female Students and Perceived Parental Rearing Attitudes. Social Behavior and Personality, 36, 765-770. http://dx.doi.org/10.2224/sbp.2008.36.6.765

[19] Turner, M., Love, S. and Howell, M. (2008) Understanding Emotions Experienced When Using a Mobile Phone in Public: The Social Usability of Mobile (Cellular) Telephones. Telematics and Informatics, 25, 201-215. http://dx.doi.org/10.1016/j.tele.2007.03.001

[20] Bianchi, A. and Phillips, J.G. (2005) Psychological Predictors of Problem Mobile Phone Use. Cyberpsychology \& Behavior, 8, 39-51. http://dx.doi.org/10.1089/cpb.2005.8.39

[21] Lacohée, H. and Anderson, B. (2001) Interacting with the Telephone. International Journal of Human-Computer Stu- 
dies, 54, 665-699. http://dx.doi.org/10.1006/ijhc.2000.0439

[22] Kuss, D.J., van Rooij, A.J., Shorter, G.W., Griffiths, M.D. and van de Mheen, D. (2013) Internet Addiction in Adolescents: Prevalence and Risk Factors. Computers in Human Behavior, 29, 1987-1996.

http://dx.doi.org/10.1016/j.chb.2013.04.002 


\section{Appendix}

\section{Wakayama Smartphone Dependence Scale: WSDS}

\section{Immersion in Internet communication}

1) I have more fun communicating with my smartphone than having real conversations.

2) Except for using my smartphone, I have no particular hobbies.

3) If the other party is slow to reply to my mail or message, I start to fall out with them.

4) I get irritated if someone speaks to me while I am using my smartphone.

5) Without a smartphone, I find it hard to communicate with my friends.

6) I express my true feelings better via email than by speaking face to face or over the phone.

7) I use my smartphone to escape from reality.

Using a smartphone for extended periods of time and neglecting social obligations and other tasks

8) My immersion in smartphone use gets in the way of my studies or work.

9) My immersion in smartphone use disrupts my daily schedule.

10) I use my smartphone when there are other tasks I should be doing.

11) My immersion in smartphone use makes me stay up late at night and I don’t get enough sleep.

12) I feel that my smartphone use time is getting longer and longer.

13) I make smartphone calls even late at night.

14) I talk on my smartphone for more than one hour a day.

Using a smartphone while doing something else and neglect of etiquette

15) I use my smartphone when I am talking with other person(s).

16) I use my smartphone when I am eating.

17) I use my smartphone when I am in the company of one or two other people.

18) I use my smartphone when I am riding on a train or in similar situations.

19) I use my smartphone even when I am at work or in class.

20) I use my smartphone when I am walking.

21) Without thinking, I check my smartphone for email or voice mail even when it hasn’t rung.

Respondents were asked to score each item as follows: Always, 3 points; Often, 2 points; Sometimes, 1 points; or Hardly ever, 0 points. Scores are then summed to provide subscale ( 7 items in each subscale) and overall scores of smartphone dependence. 